\title{
Pandemia e Antiguerra: da lógica da acumulação à lógica do cuidado
}

\author{
Pandemic and Antiwar: from the logic of accumulation to the logic of care
}

\section{Victor Ximenes Marques*}

Resumo: A pandemia do novo coronavírus oferece um desafio ao pensamento: pensar a disrupção dos assuntos humanos causada por um agente inumano. Nossa capacidade coletiva de lidar com o problema dependerá, também, dos enquadramentos conceituais que seremos capazes de mobilizar. Este ensaio busca analisar a metáfora da guerra e a sua pertinência epistêmica, abordando os discursos que a mobilizam e as críticas que a rejeitam. Concluímos que a metáfora carrega um momento de verdade em sua forma, apesar do sinal trocado quanto ao conteúdo. Se a guerra é uma suspensão temporária da lógica da acumulação pela lógica da destruição, sugerimos uma substituição (permanente?) da lógica da acumulação pela lógica do cuidado.

Palavras-chave: Pandemia; Guerra; Coronavírus; Cuidado; Reprodução Social

Abstract: The new coronavirus pandemic offers a challenge to thought: how to think about the disruption on human affairs caused by an inhuman agent. Our collective capacity to deal with the problem also depends upon the conceptual frameworks that we are able to mobilize. This essay seeks to analyze the metaphor of war and its epistemic relevance, addressing discourses that mobilize it and the criticisms that reject it. We conclude that the metaphor carries a moment of truth in its form, although the content must be inverted. If war is a temporary suspension of the logic of accumulation by the logic of destruction, we suggest to substitute (permanently?) a logic of care for the logic of accumulation.

Keywords: Pandemic; War; Coronavirus; Care; Social Reproduction

\section{Introdução}

O novo coronavírus apresenta uma dificuldade peculiar para a filosofia. A intrusão de um fator inumano, operando em uma escala imperceptível aos nossos sentidos, nos condena a uma ansiedade permanente frente a sua ininterrupta presença espectral. Como fenômeno ao mesmo tempo inacessível à apreensão imediata e, no entanto, radicalmente presente, o momento pandêmico confronta o senso comum com a impossibilidade de conceber e de interpretar a nova ameaça: O que o vírus quer? Como imaginá-lo? Como interpretar suas "intenções"? Tal invisibilidade angustiante se soma à dificuldade de compreensão do próprio comportamento viral, dado que sua dinâmica biológica específica é indiferente aos assuntos humanos - os atravessa sem se importar com eles. Contudo, as atividades deste "agente" um "sujeito automático", sem intencionalidade, mas com um telos reprodutivo expansivo são profundamente disruptivas para os assuntos humanos. $\mathrm{O}$ pensamento é obrigado a se debruçar sobre um “corpo estranho" que irrita, profundamente, nosso metabolismo tanto biológico quanto social - por dentro, e por meio, dos corpos -, resultando em uma situação dramática de proporção planetária. Uma condição que se impõe, aliás, mesmo na ausência de qualquer tentativa de dar conta simbolicamente do vírus, ainda que as tentativas de 
simbolizá-lo não faltem, e que também elas tenham suas próprias consequências metabólicas, em várias escalas.

Não há, claro, nada de novo em uma infecção: trata-se de um fato banal da vida biológica, com o qual todo o ser vivo, incluindo aí qualquer ser humano, se vê obrigado a lidar em algum momento, seja esse organismo capaz ou não de entender o que se passa no interior de seu corpo. O mesmo vale para as dinâmicas epidemiológicas que incidem sobre a espécie, no nível populacional. $\mathrm{O}$ que um patógeno novo para a espécie humana - cuja novidade mesma é o que desafia nosso sistema imunológico, e que por isso se espalha tão rapidamente por um mundo humano hiper-conectado e acelerado - nos força a fazer é parar. $\mathrm{O}$ distanciamento físico, a quarentena, melhor estratégia disponível como freio à contaminação, é uma abrupta desaceleração dos fluxos. A interrupção do ritmo da "normalidade" como política emergencial para salvar vidas nos oferece a oportunidade, também, de uma suspensão do pensamento. Parar para refletir sobre nossa própria fragilidade pode também nos sugerir a ocasião para articular teoricamente nosso pertencimento corpóreo e relacional à natureza, com sua miríade de fatores e agentes inumanos e invisíveis. Afinal, são sempre e necessariamente as precárias condições materiais (corpóreas e biológicas) que suportam nossas elevadas atividades "espirituais" - do pensamento à política.

A reflexão que se segue é construída na chave do que se poderia chamar de um "materialismo naturalista crítico", um ponto de partida conceitual que reconhece a existência dura de uma realidade objetiva alheia aos anseios e interpretações humanas, e que compreende o próprio humano como um produto tardio e contingente de uma história natural que o excede e o antecede. Naturalista porque enxerga todo o fenômeno humano como parte da natureza e, portanto, frágil, precário, atravessado por processos materiais que escapam à nossa intuição, mas que constituem a base e a condição de possibilidade material, ineliminável, de qualquer vida (seja livre ou nua). E crítico porque aponta que os arranjos sociais que realizam a necessária mediação metabólica entre humanidade e o restante da natureza são não-naturais: instituídos historicamente e contingentes dentro de certos limites, passíveis, portanto, de intervenção política consciente e criativa.

A emergência da pandemia e o choque social daí decorrente são sintomáticos, assim como um bom ponto de partida reflexivo, para um materialismo naturalista crítico. A ilusão de que os humanos são soberanos nos assuntos humanos se desmonta espetacularmente quando a presença inesperada de um microscópico patógeno é suficiente para mudar a maneira como nos relacionamos uns com os outros, como nos distribuímos e nos movemos pelo espaço. Ao que tudo indica, para além de seus efeitos imediatos, a pandemia está produzindo, também, consequências de larga duração, em várias esferas, que vão desde o comportamento individual ao funcionamento das economias e das relações entre os países. As categorias que usamos para organizar nossa experiência de mundo, bem como nossos hábitos de pensamentos, estão sendo reconfigurados pelas múltiplas implicações trazidas pelo vírus.

Atravessando escalas, o patógeno produz efeitos em cascata, do micro ao macro, indiferente às preocupações humanas. $O$ pensamento, no entanto, não pode se dar ao luxo de reproduzir essa indiferença: o vírus e suas consequências nos interessam (muito), e tematizar explicitamente as transformações em curso é obrigação de um esforço filosófico à altura de nosso tempo. Dos inúmeros caminhos possíveis, nos limitamos a uma pergunta curta, quase ingênua: estamos em guerra? A resposta não é simples, e a tentativa de articulála, como já veremos, nos leva a destinos inesperados. 


\section{Estamos em guerra contra um vírus?}

Para alguns a resposta é tão simples quanto a pergunta. O congresso brasileiro, por exemplo, aprovou uma emenda constitucional apelidada de "orçamento de guerra". Em 18 de março, Donald Trump se auto-designou um "presidente de tempos de guerra”, referindo-se ao momento como "nossa guerra contra o vírus chinês" e declarando:

Toda geração de americanos foi chamada a fazer sacrifícios compartilhados pelo bem da nação. [...] Agora é a nossa hora. Devemos nos sacrificar juntos, porque estamos todos juntos nisso, e passaremos juntos por isso. É o inimigo invisível. Esse é sempre o inimigo mais difícil, o inimigo invisível' ${ }^{1}$.

Poucos dias antes, em 16 de março, o presidente francês, Emmanuel Macron, a antítese aparente de Trump, havia proferido um discurso em que repetiu seis vezes a frase "estamos em guerra", e se referiu ao vírus como um "inimigo, invisível, elusivo e avançando"2.

A metáfora da guerra tem sido mobilizada, não de hoje, por grupos de poder assentados na máquina estatal sob a finalidade, mais ou menos consciente, de inflar a própria legitimidade a partir da narrativa de um inimigo comum e excepcional. $\mathrm{O}$ objetivo seria criar um ambiente no qual a população esteja mais disposta a tolerar (ou mesmo deseje ativamente) medidas autoritárias e a degradação dos espaços públicos democráticos. E, no entanto, a imagem da guerra tem sido evocada também em desabafos genuínos e consternados de médicos, e demais trabalhadores da saúde, que se expõem na "linha da frente" do enfrentamento à pandemia. Nessa descrição marcial da emergência sanitária, as UTI's se convertem em trincheiras, os enfermeiros na infantaria, os hospitais lotados em campos de batalha onde se corre contra o tempo, enquanto o inimigo não cessa de provocar baixas - o cenário é de desespero, devastação, terra arrasada. Como em uma guerra, os soldados precisam de mais recursos, muitas vezes escassos: mais leitos de hospital, mais máscaras, mais respiradores. Sofrem de exaustão, de estafa física e mental, se traumatizam com a frequência com a qual precisam testemunhar sofrimento e morte. É preciso "apoiar as tropas”, armá-las de instrumentos adequados para lidar com uma ameaça existencial, que se impõe como questão de vida ou morte.

No dia 26 de março, o secretário-geral da ONU, Antonio Guterres, abria seu pronunciamento na reunião do G20 afirmando: "estamos em guerra com um vírus - e não estamos ganhando"3. O apelo sugeria que para uma ameaça da magnitude de uma guerra se deve montar um plano de "tempo de guerra", um esforço concertado em larga escala a partir de uma estratégia comum.

Os paralelos são tão reais quanto as "desanalogias". O principal paralelo a ser apontado é que nas guerras totais (os exemplos clássicos são a primeira e a segunda guerras mundiais) mesmo as sociedades capitalistas se veem obrigadas a suspender certas lógicas econômicas. A competição é suavizada pela necessidade de solidariedade social interna, a anarquia do mercado é substituída pelo foco no planejamento, os interesses particulares submetidos ao interesse geral - uma única tarefa a ser cumprida, custe o que custar: vencer.

\footnotetext{
1 "Remarks by President Trump, Vice President Pence, and Members of the Coronavirus Task Force in Press Briefing”, 18 de março de 2020: https://www.whitehouse.gov/briefings-statements/remarkspresident-trump-vice-president-pence-members-coronavirus-task-force-press-briefing-5/

2“«Nous sommes en guerre»: le verbatim du discours d'Emmanuel Macron”, 16 de março de 2020: https://www.lemonde.fr/politique/article/2020/03/16/nous-sommes-en-guerre-retrouvez-le-discours-demacron-pour-lutter-contre-le-coronavirus 6033314 823448.html

3"This war needs a war-time plan to fight it", 26 de março de 2020: https://www.un.org/en/coronavirus/warneeds-war-time-plan-fight-it
} 
Na situação de extrema necessidade, cresce a demanda para que os negócios privados se subordinem ao bem comum, a partir de uma racionalidade pública. Tempos de guerra exigem, precisamente, para fazer referência às palavras do diretor chefe da Organização Mundial da Saúde (OMS), Tedros Ghebreyesus, "uma abordagem coletiva coordenada e abrangente que envolva todo o mecanismo do governo" 4 .

O blog oficial do Fundo Monetário Internacional (FMI) publicou, no começo de abril, um artigo intitulado "Políticas econômicas para a guerra COVID-19"5 que abre com a afirmação: "a pandemia do COVID-19 é uma crise como nenhuma outra. Parece uma guerra, e de muitas maneiras é mesmo. Pessoas estão morrendo. Profissionais médicos estão na linha de frente. Aqueles em serviços essenciais, distribuição de alimentos, entrega e serviços públicos trabalham horas extras para apoiar o esforço”. Os autores ressaltam que a principal característica compartilhada entre a pandemia e a guerra é a exigência de "um aumento do papel do setor público". Essa ampliação, segue o argumento, pode envolver "ações intrusivas do governo [no mercado] para fornecer suprimentos essenciais por meio do recurso a poderes de guerra, com priorização de contratos públicos para insumos e bens finais críticos, e reconversão de indústrias ou nacionalizações seletivas".

Não por acaso, a pandemia tem revertido em um pico de popularidade para ideias econômicas historicamente associadas a John Maynard Keynes, fenômeno batizado por alguns de um "keynesianismo de coronavírus". O próprio Keynes já desconfiava que suas recomendações econômicas - que envolviam o abandono da mentalidade do laissez-faire, a ampliação do investimento público, e o controle deliberado de certas variáveis econômicas chaves segundo o interesse social $^{6}$ - talvez exigissem uma guerra para se tornarem politicamente viáveis.

\section{Estamos em guerra contra um vírus?}

No Brasil, é provável que o crítico mais vocal à metáfora da guerra seja o professor Acácio Augusto, da UNIFESP. Desenvolvendo uma análise de evidente inspiração foucaultiana, no artigo intitulado "Guerra e pandemia: a produção de um inimigo invisível contra a vida livre" 7 , Augusto nos insta a jamais usar a metáfora da guerra para "se referir a uma luta que é pela vida de cada um e não pela morte de um inimigo invisível e intangível”. A metáfora, longe de uma nomeação inocente, nos alerta o texto, serve aos interesses dos que almejam "controle social e político total", e que estão dispostos a explorar a pandemia para esses fins. Para Augusto, há tanto boas razões conceituais quanto ético-políticas para recusar decididamente a metáfora. Do ponto de vista cognitivo, estaríamos diante de fenômenos tão díspares que o paralelo só serviria para criar confusão, não tendo qualquer valor epistêmico. A guerra, argumenta o autor, segue um roteiro definido: "há objetivos, um inimigo declarado, etapas a serem cumpridas, planos de ação e hierarquia dos agentes, gente treinada para matar”. Nesta passagem, incidem já diretamente as razões ético-políticas para recusar o modelo marcial: médicos e enfermeiros não são soldados. Não são "gente treinada

\footnotetext{
4The Head of the World Health Organization (WHO) Dr. Tedros Ghebreyesus today (5 Mar) told reporters in Geneva that the COVID-19 epidemic 'can be pushed back, but only with a collective coordinated and comprehensive approach that engages the entire machinery of government'.", 05 de março de 2020: https://www.unmultimedia.org/tv/unifeed/asset/2538/2538599/

5“Economic Policies for the COVID-19 War", 1 de abril de 2020: https://blogs.imf.org/2020/04/o1/economicpolicies-for-the-covid-19-war/

${ }^{6}$ KEYNES, The General Theory of Employment, Interest, and Money, 1936.

7AUGUSTO, Guerra e pandemia: a produção de um inimigo invisível contra a vida livre, 2020.
} 
para matar", ao contrário, sua atividade é a do cuidado. Mobilizar a retórica de guerra, nesse contexto, não passa de uma convocação ao sacrifício - embora Augusto não faça referência direta a Trump, este é o entendimento que o discurso do presidente dos Estados Unidos corrobora perfeitamente. Ao aceitarmos a declaração de guerra, prossegue o argumento, naturalizamos as mortes como inevitáveis e, ainda, cedemos nossas liberdades em nome do exercício de um poder excepcional autorizado a fazer "o que for necessário" para derrotar o inimigo. Porém, como observa Acácio, não há nenhum inimigo externo a ser derrotado: o vírus não está do lado de fora, mas do lado de dentro - "como conter a 'invasão' de algo que já está entre nós e que habita invisível e virtualmente cada um dos corpos"?

Nesse ponto, a argumentação de Augusto se aproxima de Agamben, que em um breve ensaio de título "Esclarecimentos"8 observou:

Não é surpreendente que, frente o vírus, se fale de guerra. As medidas de emergência nos obrigam de fato à vida em condições de toque de recolher. Mas uma guerra com um inimigo invisível que se esconde em todas as outras pessoas é a mais absurda das guerras. É, na realidade, uma guerra civil. O inimigo não está do lado de fora, está dentro de nós.

Trata-se de uma linha de pensamento que o filósofo já havia iniciado no final do mês de fevereiro, quando escreveu que as medidas que os governos começavam a implementar para lidar com a pandemia eram "frenéticas, irracionais e totalmente desmotivadas", e que a "invenção de uma epidemia" oferecia um pretexto ideal para ampliar os procedimentos de exceção ${ }^{9}$. O terror frente ao vírus, que levaria os cidadãos a desejarem ativamente o estado de exceção, e sacrificar tanto (amizade, afeto, convicções, liberdades, etc.) em nome da vida biológica nua, seria o sintoma de uma sociedade que não tem "outro valor senão a sobrevivência”.

Como observa Augusto, em Michel Foucault a tecnologia política disciplinar está fundamentalmente associada ao "modelo da peste" (mais até que ao da guerra, inclusive). Em "Vigiar e Punir"10, Foucault descreve as medidas governamentais para lidar com uma peste em Vincennes, na França, durante o século XVII. As medidas incluem o que chamaríamos hoje de um lockdown, no estilo Wuhan: as pessoas confinadas em suas casas, vigiadas por funcionários do governo para que não saiam, as ruas ocupadas por guardas que inspecionam a população. A peste, como forma "real e imaginária" de desordem, serviu historicamente, portanto, para legitimar a penetração da regulamentação governamental "nos mínimos detalhes da vida cotidiana". A guerra total contra a peste exige o controle total sobre os corpos. Essa é a preocupação que parece conectar a reflexão de Augusto com a de Agamben - uma recusa a uma vida que é mera sobrevivência, e a afirmação de que o vírus não é o inimigo, e sim apenas um dos tantos encontros perigosos que fazem parte da vida. Os verdadeiros inimigos, na verdade, seriam aqueles que querem se aproveitar da epidemia para expandir seu poder. Nessas análises, para ir direto ao ponto, o inimigo é mais precisamente o Estado.

\section{Um esforço de anti-guerra}

É difícil não ficar com a impressão, contudo, que tanto a formulação de Augusto quanto a de Agamben minimizam a gravidade do problema. Em ambos os casos, o foco não

\footnotetext{
${ }^{8}$ AGAMBEN, Chiarimenti, 2020.

${ }^{9}$ AGAMBEN, L'invenzione di un'epidemia, 2020.

${ }^{10}$ FOUCAULT, Vigiar e punir, 1987.
} 
é tanto em como devemos lidar com a ameaça, mas um alerta sobre como os poderes estabelecidos podem explorá-la para expandir o controle, a vigilância, os procedimentos de exceção. É evidente que esses poderes (privados ou estatais) buscam efetivamente mobilizar a retórica de guerra para ampliar a subordinação da vida. Reduzir a pandemia a mais um dos perigos da vida não parece ser, no entanto, uma alternativa viável ao pensamento, pois o que a rejeição abstrata da metáfora da guerra acaba deixando de lado é que se trata de um perigo bastante específico, que demanda uma resposta determinada, com coordenação e planejamento em larga escala. O que se faz de fato necessário, sobretudo, é a capacidade efetiva de mobilizar o conjunto da sociedade de forma concertada. Nesse sentido, parte das soluções preferidas por Augusto para lidar com o problema - "autocuidado", "apoio mútuo", "ação direta" - erram o alvo. Não porque sejam condenáveis em si, mas porque são incomensuráveis com a escala na qual a questão precisa ser abordada. A preferência anarquista pela "ação direta" sinaliza certa impotência, relativa à hesitação em encarar a necessidade de ação INdireta, isto é, ação coletiva institucionalizada, exercida por mediações governamentais, no nível da racionalidade pública, de uma comunidade racionalmente dirigida.

Aí está a ambiguidade do modelo da guerra, que desafia uma rejeição total e apressada de seu uso. O momento de verdade da metáfora é chamar atenção para a escala necessária de ação coordenada, assim como para exigência de uma racionalidade pública acima dos interesses privados - que implica também a passagem das mediações mercantis para mediações explicitamente políticas. No entanto, se no nível da escala e dos procedimentos precisamos efetivamente de esforço coletivo análogo ao de tempos de guerra, no conteúdo trata-se justamente do oposto. Ao focar no conteúdo, predominam as "desanalogias": não há, de fato, nenhum exército inimigo a ser liquidado, nenhuma fronteira a ser defendida. Augusto tem razão ao sublinhar que se trata de uma luta pela vida, precisamente o oposto do que ocorre na guerra. Cabe destacar: uma luta pela vida que, a princípio, diz respeito a toda a humanidade, e mais bem deveria reforçar nossa capacidade de colaboração internacional e de solidariedade entre todos os povos. Um problema de "saúde global" requer, igualmente, uma abordagem global integrada e coerente.

A inversão de sinal se aplica inclusive para o conteúdo propriamente econômico de uma semelhante mobilização social de enfrentamento à pandemia, que, em vários aspectos, estaria mais próxima a uma DESmobilização planejada. Enquanto tempos de guerra exigem mobilização total de uma economia operando em plena capacidade, com todos os recursos humanos e materiais empregados, o que é preciso para lidar com o período agudo da epidemia é precisamente o contrário: desmobilizar amplos setores da economia, colocá-los como em hibernação, em modo de espera, para garantir o distanciamento físico. Trata-se, portanto, de uma espécie de "decrescimento" emergencial. O distanciamento físico, indispensável para achatar a curva de contágio, implica, necessariamente, uma disrupção gigantesca no mercado de trabalho (formal e informal), estando seu sucesso condicionado a uma adequada intervenção governamental planejada.

James Medway, em artigo para a Tribune Magazine, chama esse esforço de desmobilização de uma "economia de antiguerra" essenciais funcionando para garantir o suprimento de bens e serviços cruciais para a reprodução da vida e colocar o restante em modo de hibernação. É o mesmo ponto que o economista Adam Tooze levantou em entrevista para a Vox:

"Pensar no que precisamos como uma espécie de mobilização em tempo de guerra me parece errar completamente. Essa é uma tarefa muito mais peculiar. A tarefa é

${ }^{11}$ MEDWAY, The anti-wartime economy, 2020. 
manter a economia respirando por aparelhos durante um período de coma induzido artificialmente enquanto abordamos o desafio da saúde pública"12.

Para que o isolamento social funcione, isto é, para que os indivíduos possam voluntariamente se auto-isolar, é preciso garantir poder de compra na mão das pessoas, ou abastecimento material direto, assim como o funcionamento contínuo dos serviços essenciais. Daí a importância de uma renda mínima universal e de medidas como a suspensão dos despejos, congelamento dos aluguéis e a continuidade de suprimento de água e de energia. São essas medidas de segurança econômica que tornariam o distanciamento social, na escala necessária, viável para a massa das pessoas trabalhadoras, e que fariam da quarentena não um privilégio dos que podem, mas um direito universal, para todos. Vale ressaltar que apenas como um direito para todos é que a quarentena pode ser vitoriosa em suas ambições sanitárias: ou funciona em nível coletivo ou simplesmente não funciona. Os gastos governamentais prioritários, portanto, não seriam, pelo menos não em um primeiro momento, para "estimular" a economia, como acontece com os pacotes fiscais em tempos de crise econômica. Não se trata de "aquecer" a economia, e sim de congelá-la conscientemente.

A imagem de um esforço de "antiguerra” é, do ponto de vista conceitual, portanto, duplamente útil. Primeiro, identifica o elemento de verdade da metáfora da guerra - há uma simetria na escala do esforço coordenado exigido, assim como na magnitude da mobilização dos poderes públicos, que implica a suspensão da dinâmica mercantil ordinária; a bem da verdade, uma mudança de lógica da operação da economia e sociedade no geral. Esse esforço coletivo, contudo, não está a serviço da destruição e da morte, como nas guerras, mas na proteção e promoção da vida - não na eliminação de um inimigo externo comum, mas na promoção da vida em comum. Em tempos de guerra, a lógica da acumulação típica da economia capitalista é temporariamente subsumida por uma lógica da destruição, na medida em que a instância estatal intervém para impor o que define como "bem comum" supremo - a sobrevivência da comunidade nacional por meio da destruição do inimigo. Na antiguerra, a lógica da acumulação é suspensa, mas não pela lógica da destruição, e sim pelo seu oposto, que poderíamos chamar de uma "lógica do cuidado". Nesse caso, é a reprodução da vida que se eleva à prioridade; nem a destruição de um inimigo externo, nem a valorização dos capitais privados. Em segundo lugar, a mobilização em larga escala dos poderes públicos e da infraestrutura técnica e social não significa, como na guerra, mobilização em massa dos corpos. Trata-se, mais uma vez, do oposto: da necessidade de uma desmobilização massiva, ainda que racional e planejada, coordenada em larga escala. Se entendermos por antiguerra a centralidade da dimensão do cuidado, então a retórica ufanista e xenófoba, a paranoia em relação ao outro, o encerramento chauvinista no endurecimento das fronteiras, a reverência às autoridades centrais e a renúncia à democracia, tão características de "tempos de guerra", aparecem como reações regressivas inúteis e deslocadas; fundamentalmente contra-produtivas.

\section{Uma antiguerra permanente?}

Se há boas razões para se ficar atento às armadilhas de usar o modelo cognitivo da guerra para simbolizar uma "luta que é pela vida", a imagem da guerra também nos oferece tanto um indispensável sentimento de urgência quanto um alerta para a necessidade de uma

${ }^{12}$ TOOZE, What both the left and the right get wrong about the coronavirus economic crisis (entrevista ao portal Vox), 2020. 
“abordagem coletiva coordenada e abrangente", incluindo "ações intrusivas" dos poderes públicos sobre os negócios privados. A forma como percebemos e enquadramos o fenômeno têm consequências sobre como agimos a respeito, em especial sobre os limites do que julgamos viável. A figura da antiguerra nos ajuda, a princípio, a visualizar a necessidade da passagem de uma lógica da acumulação à lógica do cuidado. No entanto, em condições que Mark Fisher denominou de "realismo capitalista"13 certamente parece difícil imaginar a possibilidade mesma da referida passagem; a lógica da acumulação adquiriu tal grau de naturalização que qualquer tentativa de confrontá-la é imediatamente taxada de "irrealista" ou "utópica", com isso se querendo dizer "fora do plano do politicamente viável". E, no entanto, o espectro de uma lógica do cuidado já está presente orientando os conflitos políticos do nosso tempo: nos debates sobre renda mínima universal, nos movimentos de massa exigindo acesso universal a saúde, na atuação coletiva de movimentos sociais em vistas à distribuição de alimentos ou máscaras a populações vulneráveis, e mesmo nas medidas extraordinárias, de expansão da proteção social, que governos de diferentes cores ideológicas ao redor do mundo, em maior ou menor medida, se viram obrigados adotar - e que em outros momentos pareceriam impossíveis. Aqui não é o espaço para esboçar um programa de transição ou traçar uma estratégia política. É útil, no entanto, concluir explorando como uma possível ampliação da nossa imaginação política poderia tornar tal programa viável, argumentando que é a nossa própria condição perene de criatura natural social, e não apenas a atual situação de emergência aguda, que o torna desejável. $\mathrm{O}$ desafio, ao mesmo tempo teórico e prático, é a partir da brecha aberta pela exceção pensar como reconfigurar a norma.

Não é incomum que medidas extraordinárias sejam introduzidas originalmente em tempos de guerra, tornando-se, em seguida, permanentes. Como reconheceu o editorial da revista The Economist: "colocar a economia em modo de esforço de guerra é, supostamente, temporário. Uma análise de 500 anos de poder governamental, no entanto, sugere outro resultado: é provável que o Estado desempenhe um papel muito diferente na economia não apenas durante a crise, mas muito depois"14. O artigo recorda que a segunda guerra mundial reforçou as demandas por sistemas de bem-estar social "do berço à cova", e que o modelo social-democrata do pós-guerra seria inimaginável se não fosse pelo esforço de guerra anterior, no qual o estado administrou vastas áreas da vida econômica.

A experiência histórica dos tempos de guerra mostra que a percepção popular sobre o que o estado é capaz de fazer é ela mesma radicalmente alterada pela execução das medidas extraordinárias. A interrupção dos "negócios como de costume" (business as usual) pode provocar alterações permanentes na imaginação política, nas expectativas da população e nos parâmetros de normalidade que regulam o senso comum. Ao final da segunda guerra mundial, boa parte do eleitorado europeu começou a se colocar a questão: se uma abordagem mais intervencionista estava correta em tempos de guerra, por que não tentá-la em tempos de paz?

Há anos pensadoras feministas de orientação marxista, como Nancy Fraser ${ }^{15}$ e Tithi Bhattacharya ${ }^{16}$, vêm argumentando que além de uma crise ambiental, social e política nossa época é marcada, também, por uma “crise de cuidado”. Essa crise de cuidado se faz evidente

\footnotetext{
${ }^{13}$ FISHER, Capitalist Realism, 2009.

${ }^{14}$ Editorial da revista The Economist, 26 de março de 2020, "Rich countries try radical economic policies to counter covid-19. History suggests that the effects will be permanent", https://www.economist.com/briefing/2020/03/26/rich-countries-try-radical-economic-policies-to-counter-

covid-19

15FRASER, Contradictions of capital and care, 2016.

${ }^{16}$ BHATTACHARYA, Social reproduction theory, 2017.
} 
quando analisamos o mundo, e as dinâmicas do capitalismo, pelas lentes da "reprodução social" - isto é, pela perspectiva da produção e manutenção da vida, levando em conta o conjunto de coisas, de atividades e de relações aí implicadas. Embora o capitalismo dependa desse aparato reprodutivo para sua existência continuada - afinal, é a condição de possibilidade de reprodução da própria força de trabalho, sem a qual a dinâmica de acumulação emperra - seu foco é a produção de mercadorias, por meio da qual se dá a valorização do valor. O resultado é uma contradição que tende à crise, como nota Fraser: "a reprodução social é uma condição de possibilidade para acumulação sustentada de capital; por outro, a orientação do capitalismo à acumulação ilimitada tende a desestabilizar os próprios processos de reprodução social em que se baseia" ${ }^{17}$. Ao discutir a atual pandemia, Bhattacharya observa: "o capital reluta em gastar qualquer parte de seus lucros em processos que sustentam e mantêm a vida. É por isso que todo o trabalho de assistência é desvalorizado ou não remunerado no capitalismo, enquanto instituições de vida, como escolas e hospitais, são constantemente privatizadas ou subfinanciadas"18. Tanto Frase ${ }^{19}$ quanto Bhattacharya ${ }^{20}$, têm destacado em entrevistas recentes que devido à pandemia a natureza essencial do trabalho de cuidado ficou mais evidente.

Situações de extrema necessidade, nas quais a própria vida se encontra sob ameaça, evidenciam a irracionalidade de submeter o direito à vida à lógica da acumulação. $\mathrm{O}$ que chamamos de lógica da acumulação é uma certa dinâmica social estruturante que prioriza e centraliza a produção de lucro e apropriação de riqueza, tendo como código fundamental a relação de propriedade. A República da Propriedade subordina a reprodução da vida ao circuito de valorização, isso é, faz a primeira depender do segundo. A consequência é que a própria cidadania tende a ser condicionada ao acesso à propriedade. Uma lógica do cuidado, ao contrário, colocaria no centro as condições de reprodução da vida, invertendo a ordem de prioridade a partir de um novo critério normativo para avaliar as políticas e intervenções de caráter público e seus efeitos na ordem econômica. O que os eventos extremos - de desastres naturais a pandemias - deixam às claras é como os mecanismos de mercado capitalistas são insuficientes, quando não disfuncionais, para a proteção da vida, e nossos saudáveis instintos morais espontaneamente se escandalizam frente aos que utilizam a soberania proprietária para tomar proveito econômico da situação. Nesses momentos, mostra-se óbvio que a razoabilidade exige às instâncias coletivas político-jurídicas, e aos governos em especial, redobrar a atuação para impor limitações democráticas à mercantilização da vida. Não é demais argumentar que tais momentos deveriam servir também, à medida que lançam luz à inescapável fragilidade e interdependência constitutivas da condição humana (de uma criatura natural que precisa de cuidado social), como impulso para um esforço permanente de ampliar a solidariedade social e o amparo institucional à reprodução da vida. Isso deve nos levar, entre outras coisas, a refletir sobre que tipo de "novo normal" queremos estabelecer para o pós-pandemia, uma vez que o velho normal estava comprometido com a sustentação permanente de uma crise ambiental e de uma crise de cuidado. A intrusão viral pode, e deve, nos inspirar a um esforço coletivo institucionalizado que ponha o centro no cuidado, orientando o pensamento e a política às dimensões ecológicas e materiais da existência humana. Nossa imaginação política e criatividade institucional devem responder a esse desafio.

\footnotetext{
${ }^{17}$ Fraser, Contradictions of capital and care, 2016.

${ }^{18}$ BHATTACHARYA, Social Reproduction Theory And Why We Need it to Make Sense of the Corona Virus Crisis, 2020.

${ }^{19}$ FRASER, Taking Care of Each Other Is Essential Work, 2020

${ }^{20}$ BHATTACHARYA, Social Reproduction and the Pandemic, 2020.
} 
Talvez, então, não devêssemos aspirar à construção de algo como um "estado de antiguerra permanente"? Ou seja, a substituição definitiva de uma lógica de acumulação por uma lógica do cuidado. É provável que tenhamos muito o que aprender com atual crise do novo coronavírus para enfrentar outros desafios sociais que batem à porta, a crise climática sendo talvez o exemplo mais evidente. Se a reconversão industrial se impõe agora como uma necessidade imediata para salvar vidas, será necessária também em uma escala ainda maior para enfrentar o aquecimento global e as mudanças climáticas, o que exige a descarbonização da economia. De modo semelhante, a crise sanitária emergencial deveria também nos lembrar da crise sanitária permanente a qual está submetida a população despossuída. Se a construção de hospitais de campanha e a injeção de recursos no sistema de saúde pública se tornam pauta do dia para evitar uma tragédia humanitária imediata, tanto melhor seria abandonar definitivamente o sub-financiamento e privatização dos serviços sociais, e garantir o tratamento médico como direito universal, oferecido por um sistema público robusto preparado para lidar com emergências e catástrofes imprevisíveis. E, por fim, se a exigência da quarentena em massa nos impõe a percepção nítida de que, como a sociedade, não podemos deixar as pessoas materialmente desamparadas, é hora de reconhecer que o direito à vida envolve também um direito universal à segurança material, para além dos mecanismos de mercado regulados pelo direito à propriedade privada. Semelhantes medidas não cairão do céu, e é bem possível que dependam da emergência de um novo tipo de agência política coletiva (ainda a ser inventada) para que sejam concretizadas; mas a expansão de nossa imaginação política, e a mudança nos parâmetros pelos quais julgamos algo como realista e viável, é um primeiro passo necessário nessa direção.

\section{Referências}

AUGUSTO, Acácio. Guerra e Pandemia: produção de um inimigo invisível contra a vida livre. Lab Zona de Contágio, 26 de março de 2020. Disponível em: https://www.tramadora.net/2020/03/26/guerra-e-pandemia-producao-de-um-inimigoinvisivel-contra-a-vida-livre/ Acesso em: 30 de abril de 2020.

AGAMBEN, Giorgio. L'invenzione di un'epidemia. Quodlibet, 26 de fevereiro de 2020. Disponível em: https://www.quodlibet.it/giorgio-agamben-l-invenzione-di-un-epidemia Acesso em: 30 de abril de 2020.

AGAMBEN, Giorgio. Chiarimenti. Quodlibet, 17 de março de 2020. Disponível em: https://www.quodlibet.it/giorgio-agamben-chiarimenti Acesso em: 30 de abril de 2020.

BHATTACHARYA, Tithi (org.). Social reproduction theory: Remapping class, recentering oppression. Londres: Pluto Press, 2017.

BHATTACHARYA, Tithi Social Reproduction Theory And Why We Need it to Make Sense of the Corona Virus Crisis. Disponível em: http://www.tithibhattacharya.net/new$\mathrm{blog} / 2020 / 4 / 2 /$ social-reproduction-theory-and-why-we-need-it-to-make-sense-of-thecorona-virus-crisis Acesso em: 30 de abril de 2020.

BHATTACHARYA, Tithi Social Reproduction and the pandemic. Dissent: 2 de abril de 2020. Entrevista a Sarah Jaffe. Disponível em: https://www.dissentmagazine.org/online articles/social-reproduction-and-the-pandemicwith-tithi-bhattacharya Acesso em: 30 de abril de 2020. 
FIHSER, Mark. Capitalist Realism: Is There No Alternative? Winchester: Zero Books, 2009.

FOUCAULT, Michel. Vigiar e Punir: nascimento da prisão. Trad. Lígia M. Ponde Vassalo. Petrópolis: Vozes, 1987.

FRASER, Nancy. Contradictions of capital and care. New Left Review, Londres, v. 100, JulhoAgosto/2016, pp. 99-117.

FRASER, Nancy. Taking Care of Each Other Is Essential Work. Vice: 7 de abril de 2020. Entrevista a Clio Chang. Disponível em: https://www.vice.com/en us/article/jgezgg/takingcare-of-each-other-is-essential-work Acesso em: 30 de abril de 2020.

KEYNES, John M. The General Theory of Employment, Interest, and Money. Londres: Palgrave Macmillan, 1936.

MEADWAY, James. The anti-wartime economy. Tribune Magazine, Londres, 19 de março de 2020. Disponível em: https://tribunemag.co.uk/2020/03/the-anti-wartime-economy Acesso em: 30 de abril de 2020 .

TOOZE, Adam. What both the left and the right get wrong about the coronavirus economic crisis. Vox: 28 de março de 2020. Entrevista a Ezra Klein. Disponível em: https://www.vox.com/2020/3/28/21195207/coronavirus-covid-19-financial-crisis-economydepression-recession Acesso em: 30 de abril de 2020. 